\title{
Study on Spray Evaporation Treatment of Desulfurization Wastewater
}

\author{
Huiqian Guo ${ }^{1}$, Jing Wang ${ }^{1}$, Jiangbo $\mathrm{Wu}^{2, *}$ (D) and Xiaoze $\mathrm{Du}{ }^{1,2, *(D)}$ \\ 1 Key Laboratory of Condition Monitoring and Control for Power Plant Equipment, North China Electric \\ Power University, Ministry of Education, Beijing 102206, China; 18612260421@163.com (H.G.); \\ 18810693889@163.com (J.W.) \\ 2 School of Energy and Power Engineering, Lanzhou University of Technology, Lanzhou 730050, China \\ * Correspondence: wujb@lut.edu.cn (J.W.); duxz@ncepu.edu.cn (X.D.); \\ Tel.: +86-(931)-2973750 (J.W.); +86-(10)-61773923 (X.D.)
}

Citation: Guo, H.; Wang, J.; Wu, J.; $\mathrm{Du}, \mathrm{X}$. Study on Spray Evaporation Treatment of Desulfurization Wastewater. Coatings 2021, 11, 418. https://doi.org/10.3390/ coatings11040418

Academic Editor: Eduardo Guzmán

Received: 20 January 2021

Accepted: 1 April 2021

Published: 4 April 2021

Publisher's Note: MDPI stays neutral with regard to jurisdictional claims in published maps and institutional affiliations.

Copyright: (c) 2021 by the authors. Licensee MDPI, Basel, Switzerland. This article is an open access article distributed under the terms and conditions of the Creative Commons Attribution (CC BY) license (https:// creativecommons.org/licenses/by/ $4.0 /)$.
Abstract: Limestone-gypsum wet flue gas desulfurization (WFGD) often produces a certain amount of wastewater with complex water quality and heavy metal pollution which should be treated properly before release. Spaying the desulfurization wastewater into flue duct and using exhausted flue gas heat for evaporation is a promising and economical technology for achieving zero wastewater discharge in thermal power plant. To enable a more in-depth understanding on evaporation of FGD wastewater spray, a visual wind tunnel test rig based on the atomized droplet laser measuring system was built to reveal the impact factors on droplet thermal-fluid behavior. The dominant impact factors such as compressed air pressure and flow rate in air-blast spray nozzle, hot air temperature and velocity in the evaporation tunnel were analyzed to discuss the droplet size distribution and evaporation performance through alternating operate condition. A discrete mathematical model that combines both Eulerian and Lagrangian framework was established to validate the experiment result. It is concluded that introducing high pressure compressed air into the nozzle can contribute to the dispersion of droplets and enhance the evaporation rate. Proper flow rate in spray nozzle is required to avoid incomplete droplets evaporation. Air temperature and velocity in the evaporation tunnel apply positive impact on droplet size distribution and evaporation performance. Numerical simulation results of both dominant factors impact on evaporation behavior and total evaporation rate showed consistency with the experimental outcome.

Keywords: flue gas desulfurization wastewater; droplet evaporation characteristics; atomized droplets; experimental evaluation; numerical simulation

\section{Introduction}

Coal-fired power plants are facing the most stringent pollution discharge policy nowadays [1,2]. The limestone-gypsum wet flue gas desulfurization (WFGD) process is the most widely used technology in flue gas desulfurization (FGD) systems and often requires a significant amount of water for the scrubbing and dissolution process [3,4]. In order to control the amount of chlorine and fluoride ions in the scrubbing slurry and avoid material corrosion of the desulfurization system, part of the slurry must be periodically discharged as desulfurization wastewater. FGD wastewater is acidic and contains great amounts of nitrite, chlorine, sulfites, mercury and heavy metals, etc., and thus should be treated before discharge or recycling [5-7]. Currently the most widely used method for desulfurization wastewater treatment is chemical precipitation including steps of neutralization, coagulation and sedimentation and clarification of the wastewater $[8,9]$. However, the traditional method has drawbacks. The high concentration of the chlorine ions in FGD wastewater is hardly thoroughly removed after chemical precipitation. Large investments in chemical reagents and evaporation pools, and the high maintenance costs of the systems 
have limited the sustainable application of chemical precipitation processes $[10,11]$. Besides, the traditional method cannot effectively remove the harmful trace element, such as selenium [12], to meet the ever increasingly stringent environmental standards.

After chemical precipitation, concentration and clarification, spraying desulfurization wastewater into the flue duct and using exhaust flue gas heat for evaporation is an effective and economical technology $[8,13,14]$. Figure 1 shows the process of spray evaporation treatment of desulfurization wastewater [15]. Firstly, wastewater mixed with compressed air is atomized into droplets through an air-blast spray nozzle. Then the droplets are injected into the flue duct between the air-preheater and electrostatic precipitator and instantaneously evaporated due to absorbing the waste heat of flue gas. After the droplets are completely evaporated, the dry matter separated from the FGD wastewater is crystallized into solid particles and captured in the electrostatic precipitator or the follow-up dust collector $[16,17]$.

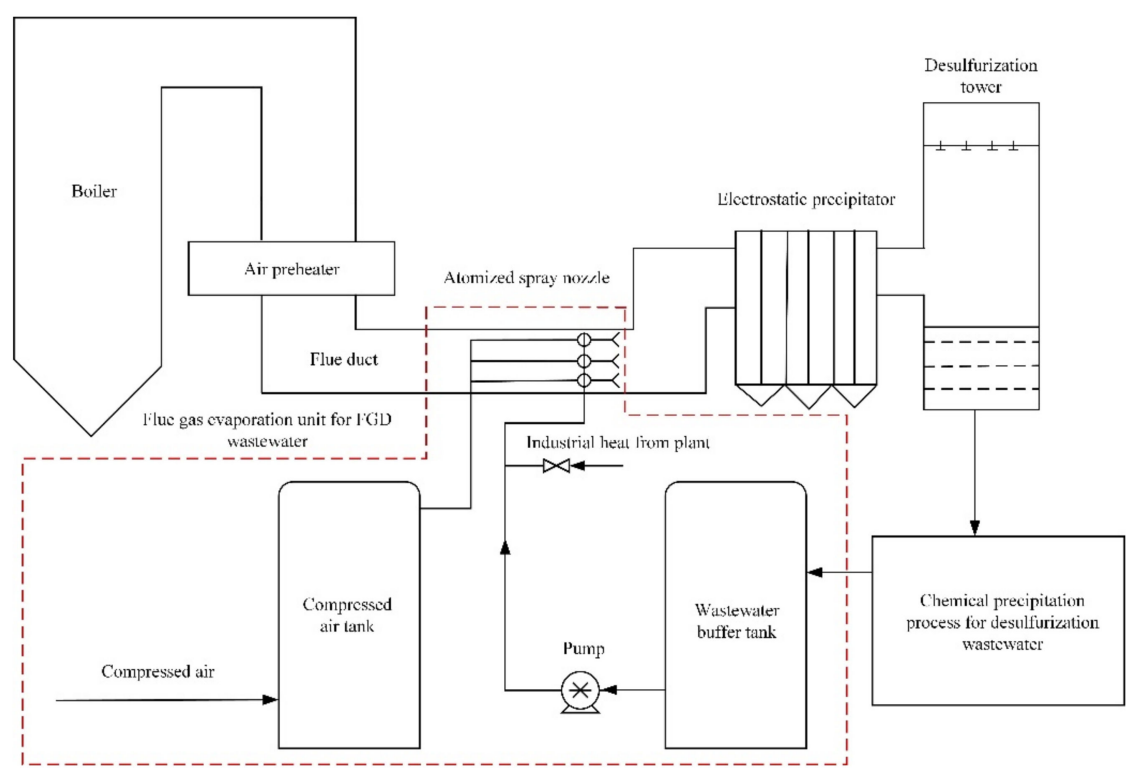

Figure 1. Typical treatment process of spraying FGD wastewater in flue duct for evaporation.

Compared to the traditional method, the FGD wastewater spray evaporation treatment has relatively low facility maintenance and it is environmentally friendly by saving energy $[18,19]$. Besides, the wastewater droplets increase the flue gas humidity, therefore reducing the electro-resistance of the fly ash and improving the dust collection efficiency in the electrostatic precipitator $[17,20]$. However, though the flue gas is unsaturated after mixing with wastewater droplets, the non-fully evaporated acidic droplets may contact with flue duct or downstream devices. In long-term operation, the incompletely evaporated droplets are corrosive to the flue duct and endanger the desulfurization equipment [8]. Therefore, it is essential to investigate the influencing factors and evaporation characteristic of FGD wastewater droplets. The key parameters include the spray equipment setup and the flue duct environmental conditions for complete droplet evaporation.

In the past, engineering practice of FGD wastewater spray evaporation has been conducted in a $330 \mathrm{MW}$ coal-fired power plant. The FDG wastewater spray system can be operated in a continuous mode, and there are no negative effects on the equipment. The results showed that this technology is feasible [15]. Further, several numerical studies have also been carried out on FDG wastewater droplet evaporation to evaluate the thermal performance, and investigate the effect of design and operating parameters (position and number of nozzles, droplet size, flue gas temperature/flow rate, spray direction, etc. [21-24]). In these studies, the droplets diameter distribution is obtained by assumption, and little or no real information is available for the validation of the numerical results. Due to these assumptions, these studies provided only qualitative conclusions and their value-add to de- 
signers is limited. Moreover, such information is essential for the optimization and design of the FGD wastewater spray evaporation. The experimental investigation of the droplets heat and mass transfer process is thus necessary. Thus far, to the best of our knowledge, few studies can be found in the literature. Although there are several pilot-scale experiments and successful cases of spray desiccation treatment, the evaporation process of the droplets is unknown due to the infeasibility of measurement.

This paper intends to make key contributions through a visualization experiment process for better investigation of droplet evaporation. A visual wind tunnel test rig equipped with a droplet laser measuring analyzer was built to observe the atomized droplet evaporation performance experimentally. The visualization of the evaporation process provides reliable experimental results and with the setup of the laser measuring analyzer, the indicator of droplet evaporation performance is quantized for further discussion. The effects of the key factors on the heat and mass transfer of the droplets are obtained for optimizing the spray evaporation. Furthermore, a combined Eulerian-Lagrangian discrete mathematical model was established to validate the experiment result. Results from both experimental and numerical analyses will be useful to better demonstrate FGD wastewater spray evaporation treatment technology.

\section{Experimental Section}

This section mainly introduces the schematic diagram of the visual wind tunnel test rig and the control system. The operate conditions of variable impact factors on evaporation performance are also presented. According to [25-27] the key factor of evaluating air-blast spray nozzle performance is the variation of the atomized droplet diameter. The Sauter mean diameter (SMD) is the most widely used parameter for demonstrating the fineness of the atomized droplet. Other than the SMD, the droplet diameter distribution that shows what diameter section the majority of the droplets fall into is also of great importance for indicating the evaporation process.

A Winner 319A atomized droplet laser measuring analyzer (Jinan Winner Particle Ltd., Shunhua Road, Jinan, China) was introduced to evaluate the droplet diameter and distribution. The laser measuring analyzer launches a laser beam into the atomized droplets field and acquires the scattering spectra to calculate the droplet diameter and distribution automatically. Figure S1 shows the schematic diagram of the laser measuring analyzer and details of the SMD and droplet diameter distribution acquisition are described in the Supplementary Material. The measurement range of the selected analyzer is 1-500 $\mu \mathrm{m}$ meanwhile the diameter of atomized droplet injected from the spray nozzle used in the experimental setup is mostly under $100 \mu \mathrm{m}$, therefore the measurement accuracy is guaranteed.

A visual wind tunnel test rig, along with the aforementioned droplet laser measuring analyzer, were built to observe and record the evaporation performance of atomized droplet. According to the reviewed numerical researches in Section 1 and taking the actual wind tunnel operate conditions into consideration, the experiment system provides different compressed air pressure, liquid flow rate in air-blast spray nozzle and the wind tunnel environment variables.

As shown in Figure 2, the experimental setup of the test rig contains injection system, water circulation, air circulation and the visual wind tunnel control system. The injection system includes air-blast spray nozzle, pressure meter and flexible tube. Compressed air and deionized water are transported into the spray nozzle through flexible tubes. The main devices in the water circulation include water tank and filter, water pump, control valve, flowmeter and flexible tubes. Deionized water is selected as the working fluid. The air circulation contains air compressor, control valve, pressure maintaining valve, pressure meter and flexible tubes. 


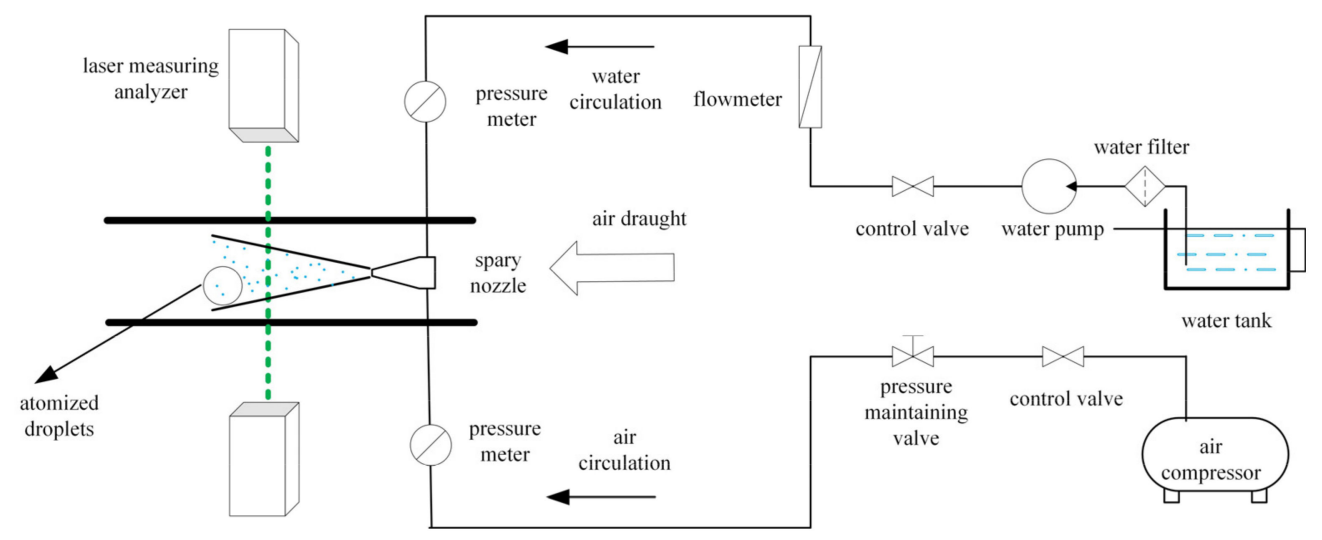

Figure 2. Schematic diagram of experimental visual system of droplet evaporation process.

The visual wind tunnel test rig shown in Figure 3 includes a draught fan, thermostat heater, visualization segment and diffusion segment. The air velocity variation in the wind tunnel is realized through altering the frequency of the draught fan. The thermostat heater can produce hot air in the temperature from $20^{\circ} \mathrm{C}$ to $90{ }^{\circ} \mathrm{C}$. The rectangle visual test rig is made of transparent acrylic material with the length of $1.6 \mathrm{~m}$ and the cross-section area of $0.3 \times 0.2 \mathrm{~m}^{2}$ in the convenience of observation. The air-blast spray nozzle is installed in the core of the cross-section at the beginning of the visual segment. Along with the horizontal line of the spray nozzle, observation holes are prepared at different length away from the nozzle for the convenience of laser measuring.

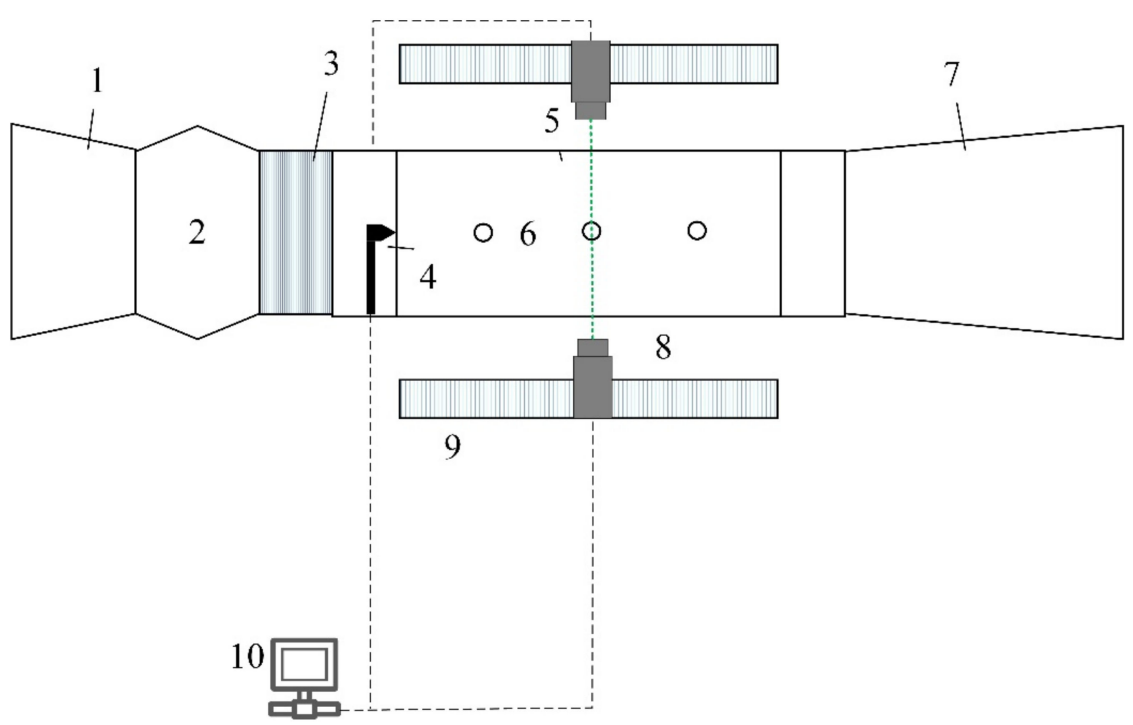

Figure 3. Schematic diagram of wind tunnel control system (1) draught fan, (2) wind tunnel, (3) thermostat heater, (4) air-blast spray nozzle, (5) visual segment, (6) observation hole, (7) diffused segment, (8) atomized droplet laser measuring instrument, (9) parallel slideway, (10) data collector.

The experiment process obtains the droplet SMD by utilizing the atomized droplet laser measuring analyzer and we can further discuss the influence factors on droplet evaporation performance by altering the compressed air pressure, flow rate in the spray nozzle and the air velocity, temperature in the wind tunnel. The observation holes are setup at the distance of $0.2,0.5,0.8,1.1$ and $1.4 \mathrm{~m}$ along the spray direction away from the spray nozzle. A typical working condition setup of the experiment includes: turning on the laser measuring analyzer and adjusting to the set position; turning on the wind tunnel thermostat heater and draught fan; turning on the air compressor and adjusting the pressure maintaining valve; turning on the water pump and adjusting the flowmeter to 
guarantee the water flow rate; collecting and saving data in the laser measuring analyzer; adjusting the analyzer to the next set position and recording data.

\section{Mathematical Model and Numerical Approach}

\subsection{Governing Equations}

The mathematical model of describing the evaporation process of atomized droplet is a discrete one, including the heat and mass transfer of continuous phase (air) and the thermo-fluid and evaporation behavior of the discrete phase (water droplets). The heat and mass transfer of continuous phase (flue gas) is described in the Eulerian coordinates. Meanwhile the evaporation of the discrete phase (water droplets) is investigated under Lagrangian coordinates.

\subsubsection{Continuous Phase (Flue Gas)}

During the evaporation process, a significant number of atomized droplets are injected into the wind tunnel. It is not realistic to neglect the influence of evaporative droplets when calculating the moving trajectory of the air flow. The mass, momentum and energy source terms of droplets are introduced into the corresponding governing equations of the continuous air flow and described as follows:

$$
\begin{gathered}
\frac{\partial\left(\rho v_{i}\right)}{\partial x_{i}}=S_{m} \\
\frac{\partial\left(\rho v_{i} v_{j}\right)}{\partial x_{j}}=\frac{\partial}{\partial x_{j}}\left[\mu\left(\frac{\partial v_{i}}{\partial x_{j}}+\frac{\partial v_{j}}{\partial x_{i}}\right)-\frac{2}{3} \mu \delta_{i j}\left(\frac{\partial v_{j}}{\partial x_{j}}\right)\right]+\rho g_{i}-\frac{\partial P}{\partial x_{j}}+S_{m o} \\
\rho v_{i} \frac{\partial E}{\partial x_{j}}=-P \frac{\partial v_{i}}{\partial x_{j}}+\frac{\partial}{\partial x_{j}}\left(\sum_{i^{\prime}}^{n} h_{i^{\prime}} J_{i^{\prime}}\right)+\frac{\partial}{\partial x_{j}}\left(K_{a} \frac{\partial T}{\partial x_{j}}\right)+\Phi+S_{e} \\
\rho v_{i} \frac{\partial Y_{i^{\prime}}}{\partial x_{i}}=-\frac{\partial J_{i^{\prime}, i}}{\partial x_{i}}+S_{m}
\end{gathered}
$$

where $J_{i^{\prime}, i}$ is the diffusion flux of $i^{\prime}$. The mass, momentum and energy sources terms of the evaporative droplets are described as parameters $S_{m}, S_{m o}$ and $S_{e}$, respectively. With the non-neglected effect of evaporative droplet on air flow, these aforementioned terms are calculated under the Lagrangian coordinate in an alternated procedure using the volume averaging method. The results are lately incorporated into the Eulerian framework.

\subsubsection{Discrete Phase (Water Droplets)}

During the evaporation process, the atomized water injected by the nozzle will break up rapidly into small droplets that follow the original flow trajectory. The droplets coinstantaneously conduct heat, mass and momentum transfer once contacted with the unsaturated surrounding air. Then the moving trajectory, diameter and temperature of droplets are altered subsequently with the formation of a saturated gas-vapor layer on the surface of the atomized droplets. Heat transfer will occur between the droplets and surrounding air due to the temperature difference between the droplet surface and the dry-bulb air temperature. In terms of the significant number of droplets, it is assumed that the heat transfer mechanism of single droplet is consistent with the droplet cluster. The following equation described the rate of absorbed energy by each single droplet:

$$
m_{d} C_{p w} \frac{d m_{d}}{d t}=h_{c} A_{d}\left(T_{a}-T_{d}\right)+\frac{d m_{d}}{d t} L_{h}
$$

where $m_{d}$ is the droplet mass, $C_{p w}$ is the droplet specific heat, $\Delta T_{d}$ is the temperature difference, $h_{c}$ is the convective heat transfer coefficient between the surrounding air and droplet, $A_{d}$ is the droplet surface area, $T_{a}$ is the air temperature, $T_{d}$ is the droplet temperature, $L_{h}$ is the vaporization water latent heat. 
Taking the droplet evaporation effect on the air flow into consideration, here we present a corresponding Nusselt number $\mathrm{Nu}$ to demonstrate the droplet heating with evaporation. The relative velocity of the droplet to the air is very small. Therefore, the Ranz-Marshall correlation is also appropriate for the droplets in this case. Thus, the convective heat transfer coefficient $h_{c}$ is described as follows:

$$
N_{u}=\frac{h_{c} D}{k_{a}}=2+0.6 R_{e_{D}}^{0.5} P_{r}^{0.33}
$$

where $N_{u}$ and $P_{r}$ are the Nusselt number and Prandtl number, respectively. $D$ is the instantaneous average diameter of droplet, $k_{a}$ is the thermal conductivity of the air, and $R_{e_{D}}$ is the droplet Reynolds number. $d m_{d} / d t$ is the mass flow rate transferred to the air by evaporation, which explains the evaporation rate of droplet and determined by the density variation between the droplet gas-liquid surface and oversaturated steam in the flow duct. $d m_{d} / d t$ is described as follows [28,29]:

$$
\frac{d m_{d}}{d t}=A_{d} h_{D}\left(\rho_{s, i n t}-\rho_{v a}\right)
$$

where $h_{D}$ is the mass transfer coefficient derived by the empirical Sherwood correlation:

$$
S h=\frac{h_{D} D}{D_{f}}=2+0.6 R_{e_{D}}^{0.5} S_{c}^{0.33}
$$

where $S h$ is the Sherwood number that describes the mass transfer process, $D_{f}$ is the vapor diffusion coefficient, $S_{c}$ is the Schmidt number.

The motion equations of the atomized droplets that abided by the Newton's second law, along with the effect of the relevant forces from the surrounding air, are incorporated into the Lagrangian coordinate to demonstrate the trajectory of the droplets. The forces impacting on the atomized droplets from the surrounding air contain gravity, buoyancy, drag force, and pressure gradient forces, such as thermophoretic force. It is essential to assume that all the droplets are independent from each other and present a uniform spherical shape, therefore the changes in moving direction and velocity of the atomized droplet are primarily caused by drag force and gravity, neglecting the impacts of other forces. The motion equation of a single droplet is present as followed [30,31]:

$$
\frac{d\left(m \vec{v}_{d}\right)}{d t}=\vec{F}_{D}+\vec{F}_{\mathrm{g}}
$$

where $v_{d}$ is the velocity of the droplet, $F_{D}$ and $F_{\mathrm{g}}$ are the drag force and gravity, respectively. The drag force can be described in terms of the drag coefficient as [32]:

$$
\vec{F}_{D}=\frac{1}{2} C_{D} \rho A_{d} v_{r}^{2}
$$

where $C_{D}$ is the drag force coefficient. The empirical correlation of spherical droplet drag force coefficient is described as:

$$
C_{D}=\frac{24}{R_{e_{D}}}\left(1+0.15 R_{e_{D}}^{0.67}\right)
$$

\subsection{Boundary Conditions and Numerical Approach}

According to the typical treatment process shown in Figure 1 and the schematic diagram in Figure 3, the visual wind tunnel test rig will be selected as the physical model. Deionized water selected as the working fluid is atomized into droplet using compressed air from the air blast spray nozzle and ejected into the wind tunnel. The physical model is established based on the visual segment of the wind tunnel. A three-dimensional physical 
model is built at the length of $1.5 \mathrm{~m}$, cross-section of $0.3 \times 0.2 \mathrm{~m}^{2}$ due to three-dimensional transport direction of the droplet, as shown in Figure 4. The spray nozzle is installed in the central position of the cross-section in wind tunnel $0.1 \mathrm{~m}$ away from the entrance. The spray nozzle is set up as diameters of $1 \mathrm{~mm}$ inside and $3 \mathrm{~mm}$ outside, spraying water and compressed air, respectively.

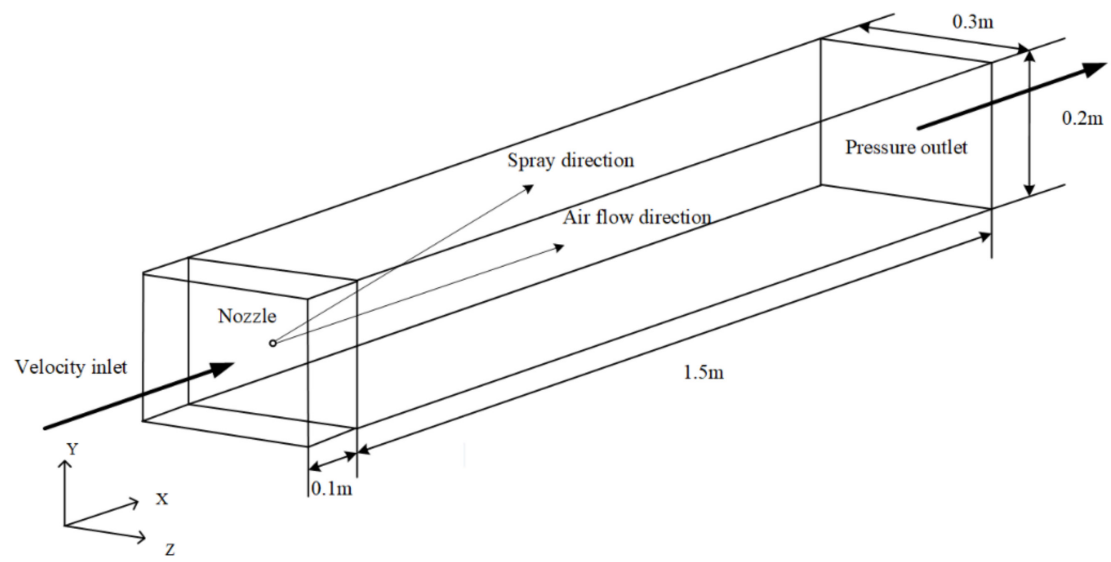

Figure 4. Physical model.

The turbulence model selected in the numerical calculation is the realizable $k-\varepsilon$ turbulence model. The 3D, Pressure-Based, Unsteady and Implicit solver is selected. On account of the liquid-gas coupling effect, the Species Transport model is adopted. The Discrete Phase model (DPM) and WAVE breakup model are selected. The atomization flow field boundary condition is set as atmospheric pressure, air velocity of $2 \mathrm{~m} / \mathrm{s}$ and temperatures of 303, 323 and $343 \mathrm{~K}$. The inlet boundary conditions for the flow field are set at the inlet velocity while the outlet boundary condition is the outlet pressure. All the computational domain side walls are prescribed as adiabatic walls. The flow field is calculated after initialization without the discrete phase water droplets.

After obtaining a steady air flow field, the air-blast-atomizer spray model is adopted to calculate the discrete phase water droplets. Parameters of the spray model are set as water temperature of $293 \mathrm{~K}$, injection time of $30 \mathrm{~s}$ and mass velocity of $0.00139,0.00278$ and $0.00417 \mathrm{~kg} / \mathrm{s}$. The inlet and outlet boundary conditions for water droplets are both set as "escape" and the wall boundary condition is adopted as "trap", which means that once the water droplets hitting the wall the calculation of the droplets will be terminated. The SIMPLE algorithm is selected for the pressure and velocity coupling. The second order upwind differencing scheme is utilized as the discretization method.

\section{Results and Analysis}

\subsection{Experimental Results}

The operational conditions of the air-blast spray nozzle and environmental variables in the flow duct are the main parameters affecting the droplet particle size distribution and evaporation rate. By using a single variable controlling method, the visual wind tunnel test rig, along with the atomized droplet laser measuring system, conduct experimental operation on impact factors of the evaporation process, including the compressed air pressure and flow rate in air-blast spray nozzle, the air velocity and hot air temperature in the flow field. It should be noted that the droplet evaporation performance is defined by the Sauter mean diameter (SMD) and the droplet diameter obeys the Rosin-Rammler distribution [26]. The distributions of droplet sizes are often fitted to mathematical functions for convenience. The Rosin-Rammler distribution function is widely used in this way [33]. Therefore, it is an assumption of the instrument without physical explanation. 


\subsubsection{Effect of Compressed Air Pressure in Air-Blast Spray Nozzle}

By introducing a compressed air flow with higher pressure far from the original injection, the air-blast spray nozzle achieves better evaporation performance and droplets undergo a two-stage breakup [34]. The primary breakup encounters in the spray nozzle cavity when compressed air is mixed with the droplets. The droplets break through surface tension and viscosity force achieving primary interaction with the compressed air flow. Then the liquid-gas two-phase flow is ejected through nozzle into the flow duct and the second breakup occurs due to the relative motion difference between the liquid-gas mixture and wind tunnel air flow. It is concluded that the air-blast spray nozzle has the advantages of preparing droplets with smaller diameter and adapting to different kinds of fluid.

The operation condition with various compressed air pressure in the air-blast spray nozzle under air temperature of $70{ }^{\circ} \mathrm{C}$, air velocity of $2 \mathrm{~m} / \mathrm{s}$, spray nozzle flow rate of $10 \mathrm{~L} / \mathrm{h}$ is demonstrated in this section. The SMD of droplets along different flow duct distance is shown in Figure 5 and the SMD distribution located at $0.5 \mathrm{~m}$ from the nozzle is seen in Figure 6.

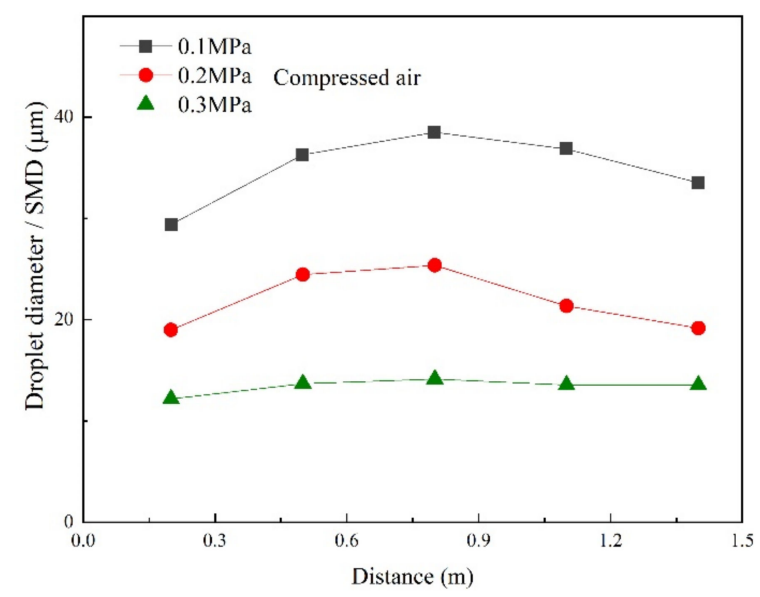

Figure 5. The droplet particle size with different compressed air pressure.

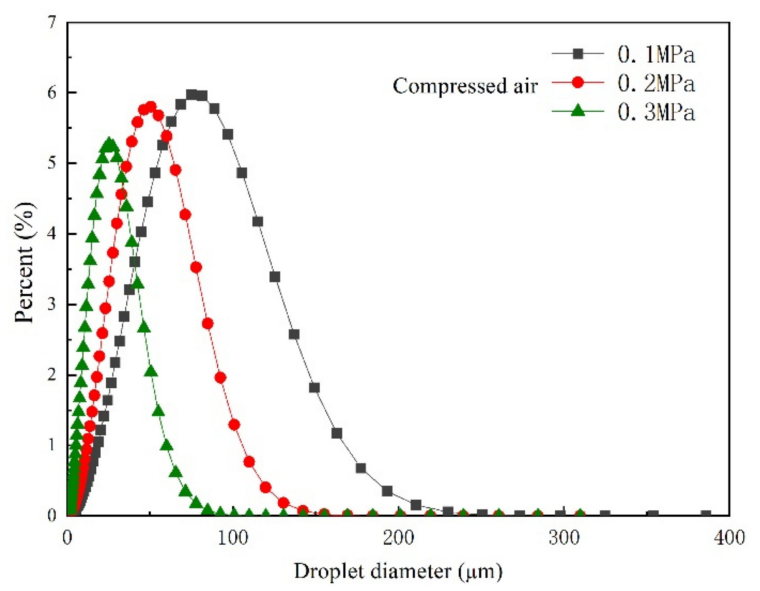

Figure 6. The droplet diameter distribution with different compressed air pressure.

It is evident from Figure 5 that the SMD with identical flow duct distance decreases as the compressed air pressure in air-blast spray nozzle increases and the variation trend is consistent with the results from the literature [16,35]. During the operation process, the SMD is observed to reduce from hundreds of micrometers to mainly under the range of $50 \mu \mathrm{m}$ when the air pressure reaches $0.2 \mathrm{MPa}$. The primary reason behind the aforementioned phenomenon could be that the droplets undergo a second breakup and shatter into 
smaller diameter particles due to the impact of compressed air instead of primary breakup with no air-blast atomization. When the air pressure reaches $0.3 \mathrm{MPa}$, the liquid-gas two-phase flow interacts more severely in the nozzle cavity and achieves better breakup through the nozzle, resulting the decrease of the SMD. Figure 6 showed the droplets diameter distribution under the Rosin-Rammler distribution. It can be seen that the peak values of the droplet diameter distribution differ under various compressed air pressures. With increased air pressure, the SMD corresponded to the peak value decreases and the cluster of droplet diameter is more concentrated in a specific region. It is concluded that the droplets evaporation performance demonstrated by the SMD is enhanced by introducing high pressure compressed air, therefore the diameter of the major droplets is shifted to a smaller value. The number of samples in the experiment is more than 1000. Therefore, according to the approach of Tate or the information theory approach developed by Panao and Moreira [36,37], the maximum deviation of the measured distribution relative to the actual one is lower than $3 \%$.

Figure 5 also reveals the variation regulation of the SMD at the different positions of the flow duct. Along with the spray direction, the SMD of droplets increase firstly and then decline. This phenomenon is mainly due to the severe collisions and coalescence between droplet particles. The droplet particles coalesce after collision in the concentrated area, resulting the increment of the SMD, then evaporated by absorbing surrounding heat along with the direction toward exit and the SMD of droplet decreases.

\subsubsection{Effect of Flow Rate from Spray Nozzle}

The droplet evaporation performance under different spray nozzle flow rate conditions with the air temperature of $70^{\circ} \mathrm{C}$, air velocity of $2 \mathrm{~m} / \mathrm{s}$, compressed air pressure of $0.1 \mathrm{MPa}$ is demonstrated in this section. Figure 7 is the droplet SMD at different flow duct distances from the spray nozzle and Figure 8 is the SMD distribution located at $0.5 \mathrm{~m}$ from the nozzle.

It is obvious from Figure 7 that the SMD of droplet decreases with a spray nozzle flow rate of $5 \mathrm{~L} / \mathrm{h}$. Obviously, as the spray nozzle flow rate increases, larger droplets appear. Moreover, as shown in Figure 7, with the increase of spray nozzle flow rate, the SMD of droplets increases at various positions. Therefore, the droplet evaporation deteriorates when the spray nozzle flow rate increases. Although a similar behavior of the SMD variation with distance shown in Figure 7, the change range of the SMD is different. Moreover, the values of the SMD at the distance of $1.4 \mathrm{~m}$ divided by the SMD in the first position are calculated. They are 1.3,1.32 and 1.33 for the spray nozzle flow rates of 5, 10 and $15 \mathrm{~L} / \mathrm{h}$, respectively. This indicates that the increase of SMD is larger with higher flow rate, i.e., the droplet evaporation deteriorates. Primary reasons of this situation could be that as the spray nozzle flow rate extends, the large number of droplets ejected from the nozzle to be evaporated hardly thoroughly spread into the surrounding area, resulting in a poor droplet diffusion situation. The total carriage effect conducted by the flow duct air on droplet particles is weakened due to the extended flow rate. Thus, the atomized droplet cannot fully contact with the flow duct air and break into fine diameter particles. Studies $[22,25,38,39]$ have showed similar results where the increased spray nozzle flow rate deteriorates the droplet evaporation rate. As indicated in Figure 7, the SMD experience a dramatic increment in the first two measure points along with the spray direction when the spray nozzle flow rate reaches 10 and $15 \mathrm{~L} / \mathrm{h}$. This could be explained by the fact that while the number of droplets ejected from the spray nozzle increases, the breakup, collision and coalescence of droplet particle are more severe in the initial section of the flow duct. When the droplets particles contact with the air flow and absorb the convection heat, moving toward the flow duct exit, the droplets evaporate and break up into particles with slightly smaller SMD. The results emphasize that a modified arrangement of multiple spray nozzles with a smaller flow rate may achieve better evaporation of droplets if the flue duct installation area is large enough. 


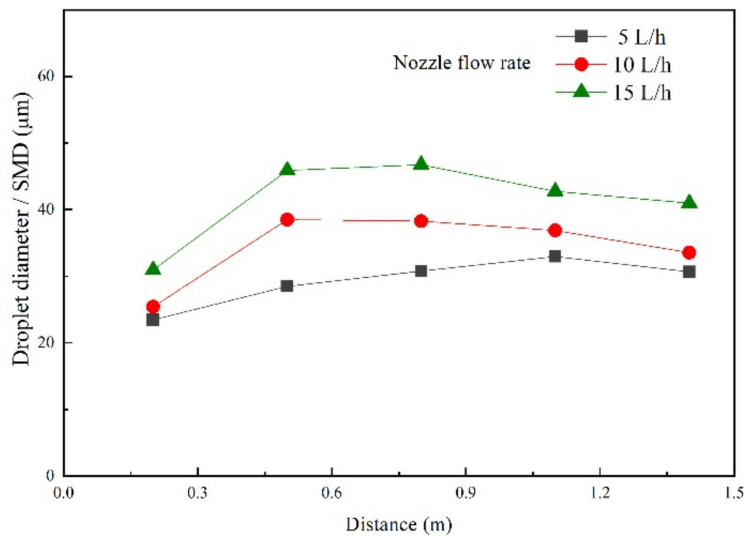

Figure 7. The droplet particle size with different spray nozzle flow rate.

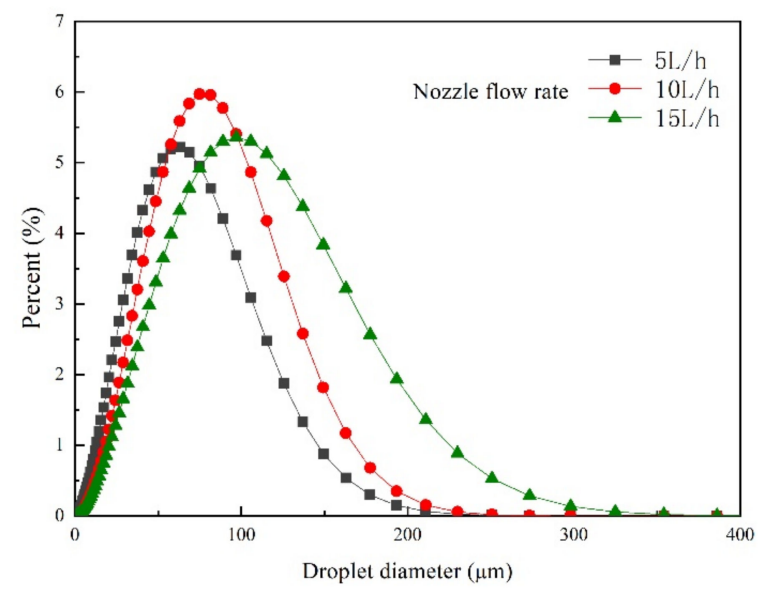

Figure 8. The droplet diameter distribution with different spray nozzle flow rate.

\subsubsection{Effect of Air Temperature}

In the visual wind tunnel test system, a thermostat heater is installed to warm up the flow duct air. In this section, operation conditions with a compressed air pressure of $0.1 \mathrm{MPa}$, air velocity of $2 \mathrm{~m} / \mathrm{s}$, and spray nozzle flow rate of $6 \mathrm{~L} / \mathrm{h}$ are tested. Results of droplet particle size (SMD) along the flow duct are shown in Figure 9 and the SMD distribution located at $0.5 \mathrm{~m}$ from the nozzle is illustrated in Figure 10.

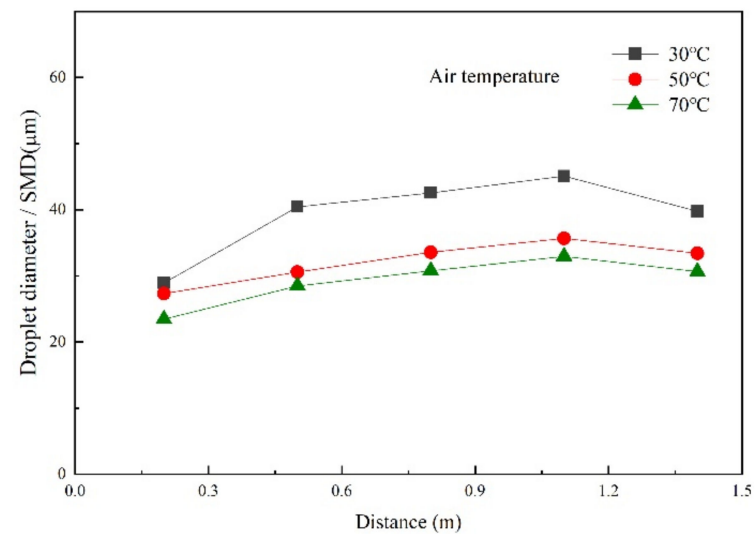

Figure 9. The droplet particle size with different air temperature. 


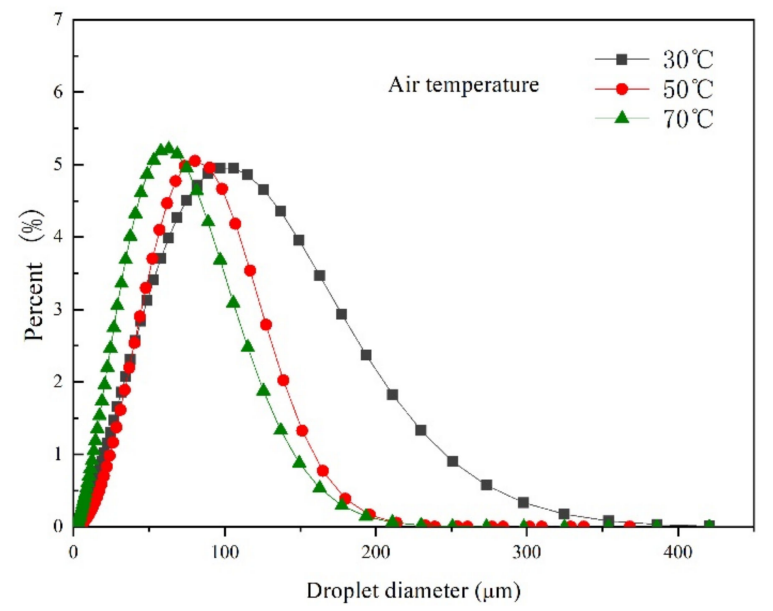

Figure 10. The droplet diameter distribution with different air temperature.

It is evident from Figure 9 that the SMD of droplets in the central segment of the flow duct undergoes an approximate $25 \%$ decline when the air temperature is increased from $30{ }^{\circ} \mathrm{C}$ to $50^{\circ} \mathrm{C}$ and $70{ }^{\circ} \mathrm{C}$. When the atomized droplets are sprayed into the unsaturated air flow, heat and mass transfer happen instantaneously due to the temperature difference between the gas-vapor layer of droplets and the surrounding air. The temperature difference between air flow and the droplet surfaces increases when the flow duct air is heated, consequently the average kinetic energy difference between droplet and the surrounding air increases $[27,40]$. The gas-liquid two-phase flow then undergoes a severe interaction and exchanges heat due to the droplet collisions. The heat and mass transfer between atomized droplets and the surrounding air is strengthened on account of the increment in air temperature, contributing to better evaporation performance of the droplets and a declination in SMD.

Figure 10 demonstrates that the droplet diameter distribution complies with the RosinRammler distribution. The cluster of droplet diameter is more concentrated as the air temperature increases and the corresponding droplet diameter of the peak value decreases. Based on information theory [41], the normalized Shannon entropy is calculated, and the results show that the values show little change with distance. Therefore, the drop size diversity is almost constant with distance. These phenomena can be explained by the aforementioned evaporation performance increment due to the heated air flow. Figure 9 also shows that the trend of SMD along the flow duct is an increscent one followed by slight decrease. The explanation of this trend is similar to the one detailed in Section 4.1.1.

\subsubsection{Effect of Air Velocity}

To investigate the dominate factors of droplet evaporation performance, the air velocity in the wind tunnel is adapted throughout different operation conditions. This section presents the droplet SMD and SMD distribution located at $0.5 \mathrm{~m}$ from the nozzle under the conditions of $0.1 \mathrm{MPa}$ compressed air pressure, $70{ }^{\circ} \mathrm{C}$ air temperature and $10 \mathrm{~L} / \mathrm{h}$ spray nozzle flow rate. The results are shown in Figures 11 and 12. 


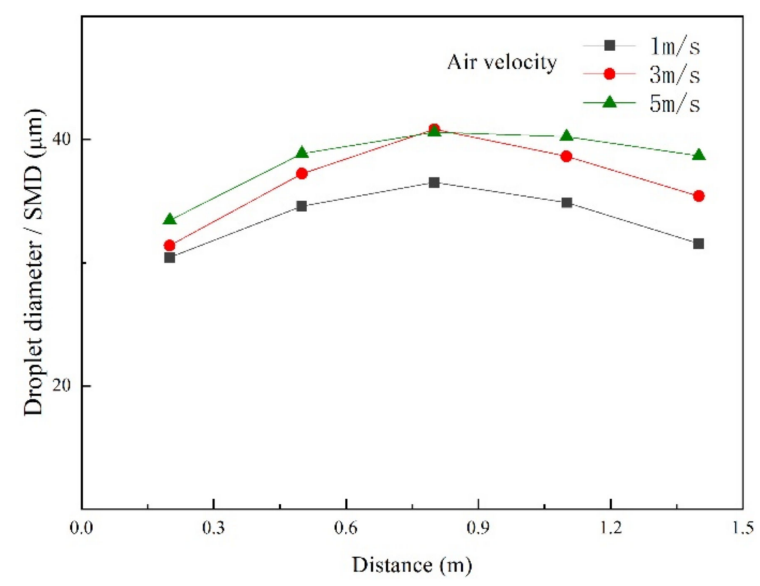

Figure 11. The droplet particle size with different air velocity.

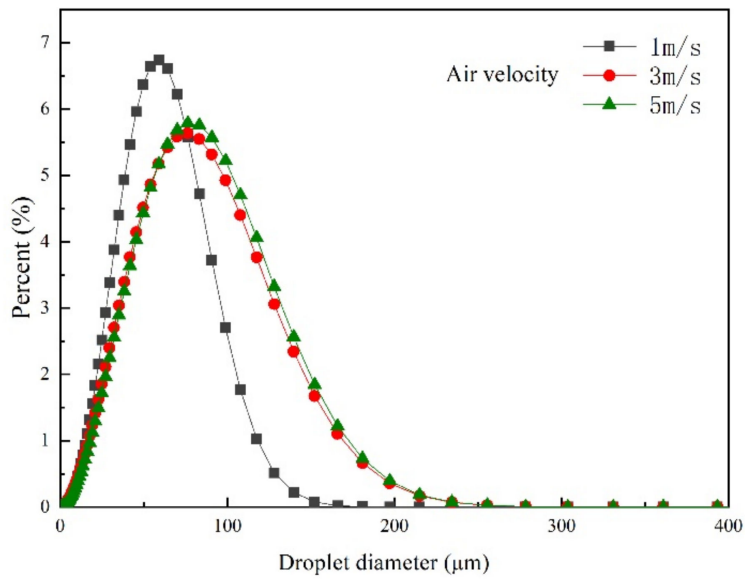

Figure 12. The droplet diameter distribution with different air velocity.

The air velocity has a contradictory impact on the heat exchange process and the droplet evaporation performance. On the one hand, a higher air velocity reinforces the relative motion between the atomized droplets and the surrounding air, therefore higher convection heat transfer rate is achieved along with the better evaporation performance. On the other hand, due to the fact that the droplet residence time plays a key role in the evaporation process, relatively high air velocity in the flow duct may result in a situation where droplets with small diameter and inertia are entrained towards the exit without further evaporation [27,42]. The total quantity of heat exchanged between atomized droplet and flow duct air is weakened, thus deteriorating the evaporation performance. Figure 11 shows that at the same test point along the spray direction, the air velocity influences the SMD on a negative way, indicating that the residence time reduction effect upon atomized droplet is stronger than the convection heat transfer enhancement. The SMD variation trends under three air velocity conditions are the same and similar to the details shows in Section 4.1.1. From Figures 11 and 12, one can notice that the variation of air velocity in the flow duct does not have a significant impact on the droplet diameter and distribution, therefore in the application of FGD wastewater evaporation process a rather low flue gas velocity is recommended for the complete evaporation of droplets.

\subsection{Simulation Results}

\subsubsection{Comparison of Experimental and Numerical Results}

Based on the experimental setup and discussion on droplet evaporation impact factors, the numerical approach investigates the droplet diameter (SMD) variation under different 
compressed air pressure, spray nozzle flow rate and wind tunnel air temperature. Results are shown in Figures 13-15, respectively.

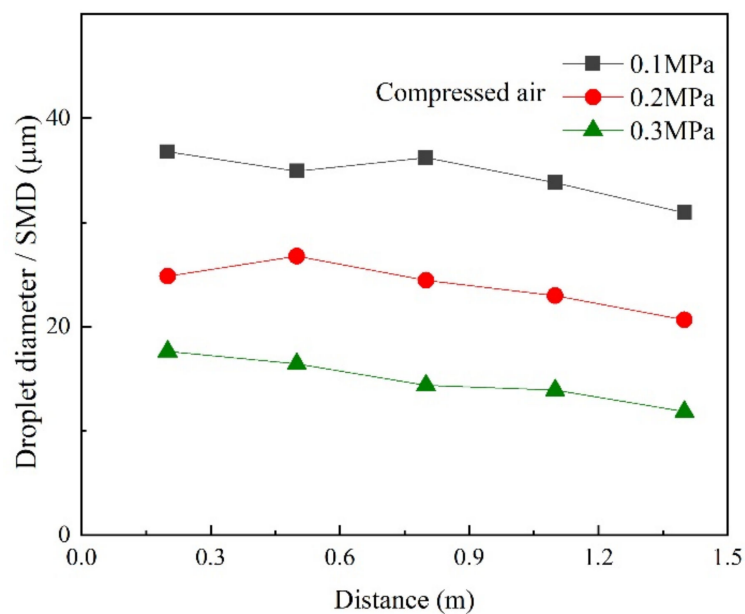

Figure 13. Effect of compressed air pressure on $\operatorname{SMD}\left(\mathrm{Q}=10 \mathrm{~L} / \mathrm{h}, \mathrm{T}=70{ }^{\circ} \mathrm{C}\right)$.

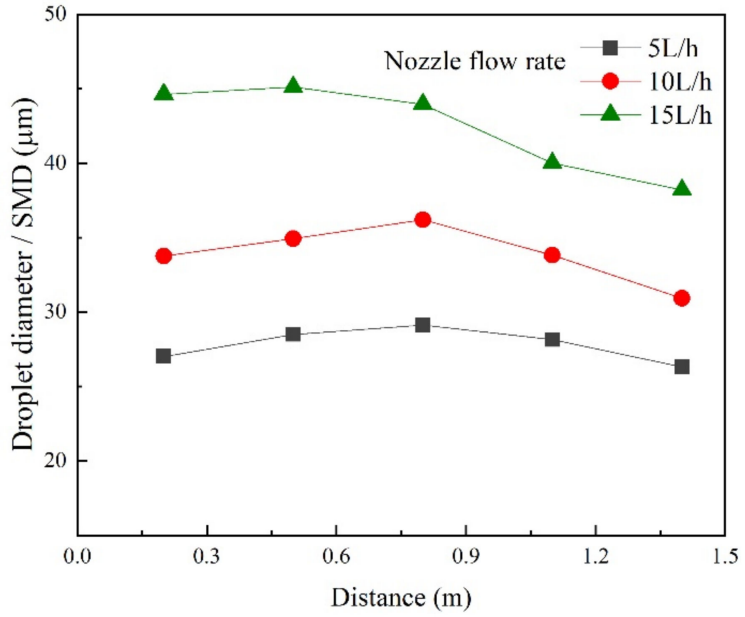

Figure 14. Effect of spray nozzle flow rate on $\operatorname{SMD}\left(\mathrm{P}=0.1 \mathrm{MPa}, \mathrm{T}=70{ }^{\circ} \mathrm{C}\right)$.

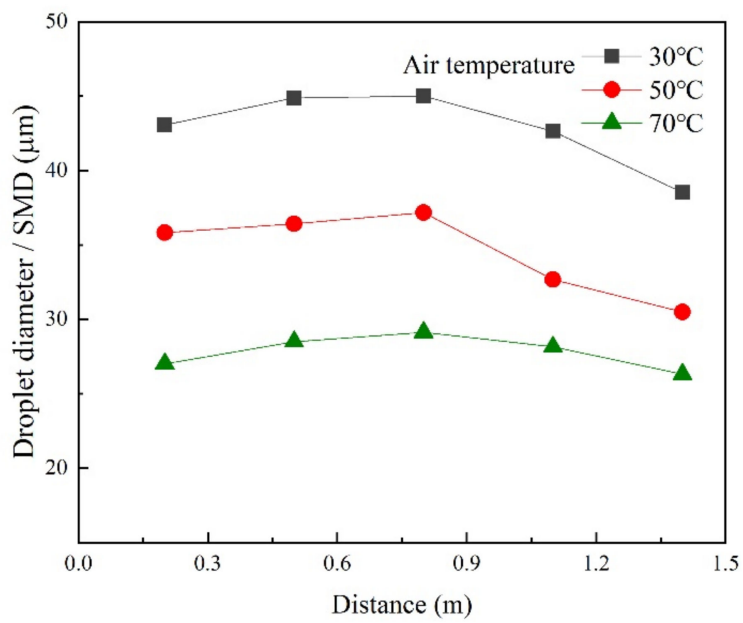

Figure 15. Effect of flow duct air temperature on $\operatorname{SMD}(P=0.1 \mathrm{MPa}, \mathrm{Q}=5 \mathrm{~L} / \mathrm{h})$. 
It can be seen from Figure 13 that consistent with the experimental results, the increasing compressed air pressure in air-blast spray nozzle resulted in a better evaporation performance of atomized droplets. Figure 14 indicates that the spray nozzle flow rate increment had a negative effect on the SMD and deteriorated the evaporation performance, which is in accord with the aforementioned results from the Experimental section. Last but not least, Figure 15 shows that a higher air temperature in the flow duct brought a better evaporate implementation and a lower SMD of droplets the same as that discussed in the experimental process.

To verify the accuracy of the selected numerical method, we presen here a comparison of the numerical and experimental results for the droplet SMD with different spray nozzle flow rates under the conditions of compressed air pressure of $0.1 \mathrm{MPa}$ and air temperature of $70^{\circ} \mathrm{C}$. It can be seen from Figure 16 that along the spray direction, the numerical and experimental results showed consistency and the deviation was within $8.2 \%$.

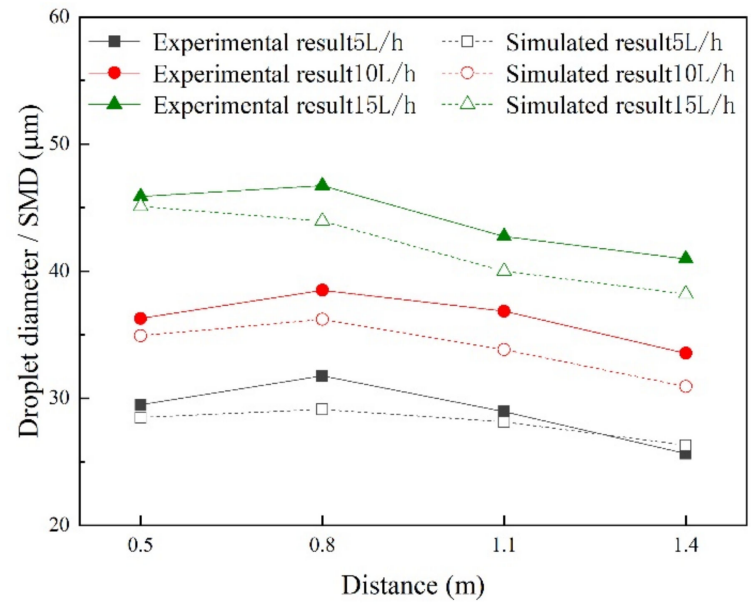

Figure 16. Comparison of experimental and numerical results.

\subsubsection{Numerical Results of the Evaporation Rate}

Figure 17 is the air temperature nephogram of the wind tunnel under the numerical simulation condition of $5 \mathrm{~L} / \mathrm{h}$ spray nozzle flow rate, $2 \mathrm{~m} / \mathrm{s}$ air velocity and $0.1 \mathrm{MPa}$ compressed air pressure. The liquid flow in the spray nozzle is shattered into small diameter droplets by compressed air and ejected conically from the nozzle. At a distance of near $0.2 \mathrm{~m}$ away from the nozzle, the droplet aggregation is obvious and only the surrounding air undergoes a temperature decrement. When the atomized droplets continue to move in the flow duct to $0.5 \mathrm{~m}$ away from the nozzle, the diffusion of droplets is spread to the flow field and the air temperature experiences a dramatic decline due to the convective heat transfer. As the spray atomization process goes on, the atomized droplets present an arch shape due to the fact that the droplets with spray direction around the nozzle axis have larger velocity than the others. The air temperature in the flow field continues to decrease as the droplet being ejected and absorbing heat for evaporation, resulting the average temperature of approximate $61^{\circ} \mathrm{C}$ at the distance of $0.8 \mathrm{~m}$ away from the nozzle, $57^{\circ} \mathrm{C}$ at the distance of $1.1 \mathrm{~m}$ away from the nozzle and $54{ }^{\circ} \mathrm{C}$ at the distance of $1.4 \mathrm{~m}$ away from the nozzle. 


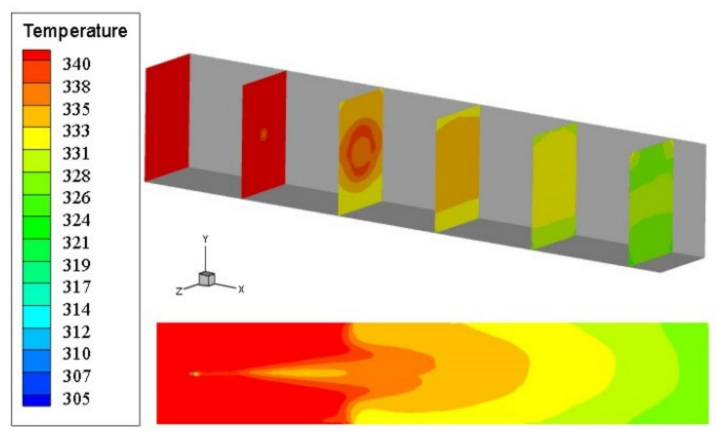

Figure 17. Air temperature nephogram of the wind tunnel.

In the evaporation process, the droplets mass flow rate transferred to the surrounding air is directly proportional to the square of the droplet diameter [25,39]. The impact of airblast spray nozzle conditions and the environmental variables of the flow duct air on SMD and diameter distribution of atomized droplets are discussed experimentally in Section 4.1. The evaporation rate under the influence factors of compressed air pressure, spray nozzle flow rate and flow duct air temperature are obtained through numerical simulation.

It can be seen from Table 1 that when the compressed air pressure is $0.1 \mathrm{MPa}$, the atomized droplet rate is $60.5 \%$ and increases to $72.4 \%$ with the compressed air pressure of $0.2 \mathrm{MPa}$. Similar to the experimental discussion in Section 4.1.1, higher compressed air pressure brought lower droplet SMD, further increasing the droplet evaporation rate. However, when the compressed air pressure continues to increase to $0.3 \mathrm{MPa}$, the droplet SMD in Section 4.1.1 decreases indicating that the evaporation performance is strengthened while the evaporation rate in Table 1 declines. This phenomenon can be explained with the possible reason that droplets ejected with higher compressed air pressure experience shorter residence time in the flow duct and part of the atomized droplets are carried out to the exit without further evaporation.

Table 1. Effect of compressed air pressure on evaporation rate and capacity $\left(\mathrm{Q}=10 \mathrm{~L} / \mathrm{h}, \mathrm{T}=70{ }^{\circ} \mathrm{C}\right)$.

\begin{tabular}{|c|c|c|}
\hline Air Pressure/MPa & Evaporation Rate/\% & Evaporate Capacity/kg. $\mathrm{s}^{-1}$ \\
\hline 0.1 & 60.5 & 0.00168 \\
\hline 0.2 & 72.4 & 0.00201 \\
\hline 0.3 & 47.9 & 0.00133 \\
\hline
\end{tabular}

Table 2 indicates the influence of spray nozzle flow rate on the evaporation rate and the results are consistent with the experimental outcome in Section 4.1.2. The droplets evaporation rate is $50.8 \%$ when the flow rate is $15 \mathrm{~L} / \mathrm{h}$ and increases to $60.5 \%$ with the flow rate decreases to $10 \mathrm{~L} / \mathrm{h}$.

Table 2. Effect of nozzle air flow on evaporation rate and capacity $\left(\mathrm{P}=0.1 \mathrm{MPa}, \mathrm{T}=70^{\circ} \mathrm{C}\right)$.

\begin{tabular}{ccc}
\hline Flow Rate/L·h $\mathbf{h}^{\mathbf{1}}$ & Evaporation Rate/\% & ${\text { Evaporate Capacity/kg } \cdot \mathbf{s}^{\mathbf{- 1}}}$ \\
\hline 5 & 78.3 & 0.00109 \\
10 & 60.5 & 0.00168 \\
15 & 50.8 & 0.00226 \\
\hline
\end{tabular}

Table 3 is the evaporation rate of atomized droplets with different flow duct air temperature. When the flow duct air is heated to $70^{\circ} \mathrm{C}$, the evaporation rate reaches $78.3 \%$. With the compressed air pressure and spray nozzle flow rate maintained the same while the air temperature drops to $50^{\circ} \mathrm{C}$ and $30^{\circ} \mathrm{C}$, the evaporation rate experiences a dramatic decrement, indicating that the convective heat transfer between droplets and surrounding air is deteriorated. The numerical results are consistent with the corresponding experimental results. 
Table 3. Effect of air temperature on evaporation rate and capacity $(\mathrm{Q}=5 \mathrm{~L} / \mathrm{h}, \mathrm{P}=0.1 \mathrm{MPa})$.

\begin{tabular}{ccc}
\hline Air Temperature $/{ }^{\circ} \mathbf{C}$ & Evaporation Rate $/ \%$ & Evaporate Capacity $/ \mathbf{k g} \cdot \mathbf{s}^{\mathbf{- 1}}$ \\
\hline 30 & 28.6 & 0.00039 \\
50 & 63.2 & 0.00087 \\
70 & 78.3 & 0.00110 \\
\hline
\end{tabular}

\section{Concluding Remarks}

Due to the confinement and inconvenience of observing and measuring the actual droplet evaporation process in the spray of FGD wastewater to the flue duct, previous studies mostly focused on the numerical simulation aspects and experimental investigations are seldomly found. In the present study, a visual wind tunnel test rig equipped with an atomized droplet laser measuring analyzer was established. Experimental observations of droplet SMD and diameter distribution were discussed and influencing factors of operating conditions were obtained. It is concluded that the air-blast spray nozzle parameters, including the compressed air pressure in nozzle cavity and spray nozzle flow rate, have a significant impact on the droplet evaporation performance. Increasing the compressed air pressure and decreasing the spray nozzle flow rate both have a positive impact on the droplet SMD and diameter distribution. When the compressed air pressure in the spray nozzle increases from $0.1 \mathrm{MPa}$ to $0.3 \mathrm{MPa}$, the droplet SMD decreases to half of the corresponding value and the diameter distribution is shifted to almost within $50 \mu \mathrm{m}$, indicating that the droplets evaporation performance is strengthened. The maximum decrement of droplet SMD along the spray direction when the spray nozzle flow rate reduced from $15 \mathrm{~L} / \mathrm{h}$ to $5 \mathrm{~L} / \mathrm{h}$ is almost $40 \%$. The flow duct air temperature is also a key heat transfer element affecting the atomized droplet evaporation. With the intense heat transfer conducted between high temperature flow duct air and atomized droplet, the droplet SMD decreases and the diameter distribution is promoted. Regarding the air velocity in the flow duct, a rather low value is recommended for a complete evaporation since the air velocity has little influence according to the experimental observation. To verify the experimental results, A discrete mathematical model that combines both Eulerian and Lagrangian framework was established. The numerical and experimental outcomes showed consistency in droplet SMD while in terms of the evaporation rate, the compressed air pressure in the spray nozzle has a limited promoting effect. The results obtained by experiments and numerical simulation will help to better demonstrate and guide the design of FGD wastewater spray evaporation technology in the future.

Supplementary Materials: The following are available online at https:/ / www.mdpi.com/article/10 .3390 / coatings11040418/s1. Figure S1: Schematic diagram of the atomized droplet laser measuring analyzer. Table S1: The droplet particle volume distribution value under different size ranges. Figure S2: The droplet particle volume distribution and the accumulation distribution curve.

Author Contributions: H.G.: Investigation, Data curation, Visualization, Writing- Original draft preparation. J.W. (Jing Wang): Visualization, Data curation, Investigation. J.W. (Jiangbo Wu).: Supervision, Reviewing and Editing. X.D. Conceptualization, Supervision, Funding acquisition. All authors have read and agreed to the published version of the manuscript.

Funding: This research was funded by National Key R\&D Program of China, Grant number 2018 YFB0604303.

Conflicts of Interest: The authors declare no conflict of interest. 


\section{Nomenclature}

\begin{tabular}{|c|c|}
\hline$A_{d}$ & droplet surface area $\left(\mathrm{m}^{2}\right)$ \\
\hline$C_{D}$ & drag force coefficient \\
\hline$C_{p w}$ & specific heat $\left(\mathrm{J} \mathrm{kg}^{-1} \mathrm{~K}^{-1}\right)$ \\
\hline$D$ & droplet average diameter $(\mu \mathrm{m})$ \\
\hline$D_{f}$ & diffusion coefficient $\left(\mathrm{m}^{2} \mathrm{~s}^{-1}\right)$ \\
\hline$E$ & internal energy $\left(\mathrm{J} \mathrm{kg}^{-1}\right)$ \\
\hline$F_{D}$ & drag force $(\mathrm{N})$ \\
\hline$F_{\mathrm{g}}$ & gravity $(\mathrm{N})$ \\
\hline g & acceleration of gravity $\left(\mathrm{m} \mathrm{s}^{-2}\right)$ \\
\hline$h_{c}$ & convective heat transfer coefficient $\left(\mathrm{W} \mathrm{m}^{-2} \mathrm{~K}^{-1}\right)$ \\
\hline$h_{D}$ & mass transfer coefficient $\left(\mathrm{m} \mathrm{s}^{-1}\right)$ \\
\hline$h_{i^{\prime}}$ & sensible enthalpy of species $i^{\prime}\left(\mathrm{J} \mathrm{kg}^{-1}\right)$ \\
\hline$J_{i^{\prime}}$ & diffusion flux of species $i^{\prime}\left(\mathrm{kg} \mathrm{m}^{-2} \mathrm{~s}^{-1}\right)$ \\
\hline$k_{a}$ & thermal conductivity of air $\left(\mathrm{W} \mathrm{m}{ }^{-1} \mathrm{~K}^{-1}\right)$ \\
\hline$L_{h}$ & latent heat of water vaporization $\left(\mathrm{J} \mathrm{kg}^{-1}\right)$ \\
\hline$m_{d}$ & droplet mass $(\mathrm{kg})$ \\
\hline$N_{u}$ & Nusselt number \\
\hline$P$ & pressure (pa) \\
\hline$P_{r}$ & Prandtl number \\
\hline$R_{e}$ & Reynolds number \\
\hline$S_{e}$ & source term of energy $\left(\mathrm{W} \mathrm{m}^{-3}\right)$ \\
\hline$S_{m}$ & source term of mass $\left(\mathrm{kg} \mathrm{m}^{-3} \mathrm{~s}^{-1}\right)$ \\
\hline$S_{m o}$ & source term of momentum $\left(\mathrm{kg} \mathrm{m}^{-2} \mathrm{~s}^{-2}\right)$ \\
\hline$S_{c}$ & Schmidt number \\
\hline$S_{h}$ & Sherwood number \\
\hline$T$ & temperature $(\mathrm{K})$ \\
\hline$T_{a}$ & air temperature $(\mathrm{K})$ \\
\hline$T_{d}$ & droplet temperature $(\mathrm{K})$ \\
\hline$v_{d}$ & droplet velocity $\left(\mathrm{m} \mathrm{s}^{-1}\right)$ \\
\hline$v_{i} v_{j}$ & air velocity components $\left(\mathrm{m} \mathrm{s}^{-1}\right)$ \\
\hline$Y_{i^{\prime}}^{\prime}$ & mass fraction of species $i^{\prime}$ \\
\hline \multicolumn{2}{|c|}{ Greek symbols } \\
\hline$\rho$ & density $\left(\mathrm{kg} \mathrm{m}^{-3}\right)$ \\
\hline$\delta_{i j}$ & mean strain tensor $\left(\mathrm{s}^{-1}\right)$ \\
\hline$\mu$ & dynamic viscosity of air $\left(\mathrm{kg} \mathrm{m}^{-1} \mathrm{~s}^{-1}\right)$ \\
\hline$\Phi$ & viscous dissipation $\left(\mathrm{W} \mathrm{m}^{-3}\right)$ \\
\hline
\end{tabular}

\section{References}

1. Jiang, B.; Xie, Y.; Xia, D.; Liu, X. A potential source for PM2.5: Analysis of fine particle generation mechanism in Wet Flue Gas Desulfurization System by modeling drying and breakage of slurry droplet. Environ. Pollut. 2019, 246, 249-256. [CrossRef] [PubMed]

2. Shi, W.; Lin, C.; Chen, W.; Hong, J.; Chang, J.; Dong, Y.; Zhang, Y. Environmental effect of current desulfurization technology on fly dust emission in China. Renew. Sustain. Energy Rev. 2017, 72, 1-9. [CrossRef]

3. Han, X.; Zhang, D.; Yan, J.; Zhao, S.; Liu, J. Process development of flue gas desulphurization wastewater treatment in coal-fired power plants towards zero liquid discharge: Energetic, economic and environmental analyses. J. Clean. Prod. 2020, 261. [CrossRef]

4. Sanku, M.G.; Karlsson, H.K.; Hulteberg, C.; Wang, W.; Stallmann, O.; Karlsson, H.T. Kinetic Evaluation of Lime for MediumTemperature Desulfurization in Oxy-Fuel Conditions by Dry Sorbent Injection. Energies 2019, 12, 2645. [CrossRef]

5. Ma, S.; Chai, J.; Chen, G.; Wu, K.; Xiang, Y.; Wan, Z.; Zhang, J.; Zhu, H. Partitioning characteristic of chlorine ion in gas and solid phases in process of desulfurization wastewater evaporation: Model development and calculation. Environ. Sci. Pollut. Res. Int. 2019, 26, 8257-8265. [CrossRef]

6. Ma, S.; Chai, J.; Wu, K.; Wan, Z.; Xiang, Y.; Zhang, J.; Fan, Z. Experimental and mechanism research on volatilization characteristics of $\mathrm{HCl}$ in desulfurization wastewater evaporation process using high temperature flue gas. J. Ind. Eng. Chem. 2018, 66, 311-317. [CrossRef]

7. Shuangchen, M.; Jin, C.; Kai, W.; Yajun, X.; Zhongcheng, W.; Jingrui, Z. Experimental and model research on chloride ion gas-solid distribution in the process of desulfurization wastewater evaporation. RSC Adv. 2018, 8, 26283-26292. [CrossRef] 
8. Shuangchen, M.; Jin, C.; Gongda, C.; Weijing, Y.; Sijie, Z. Research on desulfurization wastewater evaporation: Present and future perspectives. Renew. Sustain. Energy Rev. 2016, 58, 1143-1151. [CrossRef]

9. Godin, A. Pretreatment of liquid industrial streams by adsorption: Challenges and perspectives. Adsorpt. J. Int. Adsorpt. Soc. 2017, 23, 349-353. [CrossRef]

10. Koralegedara, N.H.; Pinto, P.X.; Dionysiou, D.D.; Al-Abed, S.R. Recent advances in flue gas desulfurization gypsum processes and applications-A review. J. Environ. Manag. 2019, 251, 109572. [CrossRef] [PubMed]

11. Gingerich, D.B.; Grol, E.; Mauter, M.S. Fundamental challenges and engineering opportunities in flue gas desulfurization wastewater treatment at coal fired power plants. Environ. Sci. Water Res. Technol. 2018, 4, 909-925. [CrossRef]

12. Córdoba, P. Partitioning and speciation of selenium in wet limestone flue gas desulphurisation systems: A review. Fuel 2017, 202, 184-195. [CrossRef]

13. Ma, Y.; Nie, Q.; Xiao, R.; Hu, W.; Han, B.; Polaczyk, P.A.; Huang, B. Experimental investigation of utilizing waste flue gas desulfurized gypsum as backfill materials. Constr. Build. Mater. 2020, 245. [CrossRef]

14. Ren, C.; Wang, W.; Mao, Y.; Yuan, X.; Song, Z.; Sun, J.; Zhao, X. Comparative life cycle assessment of sulfoaluminate clinker production derived from industrial solid wastes and conventional raw materials. J. Clean. Prod. 2017, 167, 1314-1324. [CrossRef]

15. Fu, J.; Hu, N.; Yang, Z.; Wang, L. Experimental study on zero liquid discharge (ZLD) of FGD wastewater from a coal-fired power plant by flue gas exhausted heat. J. Water Process Eng. 2018, 26, 100-107. [CrossRef]

16. Li, C.; Li, G.; Zhang, S.; Wang, H.; Wang, Y.; Zhang, Y. Study on the pyrolysis treatment of HPF desulfurization wastewater using high-temperature waste heat from the raw gas from a coke oven riser. RSC Adv. 2018, 8, 30652-30660. [CrossRef]

17. Bin, H.; Yang, Y.; Chunmin, Y.; Lin, Z.; Linjun, Y. Improving the electrostatic precipitation removal efficiency by desulfurized wastewater evaporation. RSC Adv. 2016, 6, 113703-113711. [CrossRef]

18. Cristóbal, J.; Guillén-Gosálbez, G.; Jiménez, L.; Irabien, A. Optimization of global and local pollution control in electricity production from coal burning. Appl. Energy 2012, 92, 369-378. [CrossRef]

19. Gude, V.G. Energy and water autarky of wastewater treatment and power generation systems. Renew. Sustain. Energy Rev. 2015, 45, 52-68. [CrossRef]

20. Ma, S.; Chai, F.; Wu, W. The numerical simulation of flue gas desulphurization wastewater spray evaporation. Comput. Appl. Chem. 2016, 33, 47-53. [CrossRef]

21. Deng, J.J.; Pan, L.M.; Chen, D.Q.; Dong, Y.Q.; Wang, C.M.; Liu, H.; Kang, M.Q. Numerical simulation and field test study of desulfurization wastewater evaporation treatment through flue gas. Water Sci. Technol. 2014, 70, 1285-1291. [CrossRef]

22. Feng, S.; Xiao, L.; Ge, Z.; Yang, L.; Du, X.; Wu, H. Parameter analysis of atomized droplets sprayed evaporation in flue gas flow. Int. J. Heat Mass Transf. 2019, 129, 936-952. [CrossRef]

23. Zhang, Y.X.; Wang, X.; Zhang, H.D.; Liu, J.Y.; Luan, T. Numerical simulation of WFGD wastewater with atomizing and crystallization treatment. Energy Sources Part A-Recovery Util. Environ. Eff. 2020, 42, 1268-1285. [CrossRef]

24. Shuang-chen, M.; Jin, C.; Jia-ning, C.; Kai, W.; Zhong-cheng, W.; Jing-rui, Z. Numerical simulation of bypass evaporation system treating FGD wastewater using high temperature flue gas. Environ. Technol. (UK) 2020, 41, 751-763. [CrossRef] [PubMed]

25. Alkhedhair, A.; Gurgenci, H.; Jahn, I.; Guan, Z.; He, S. Numerical simulation of water spray for pre-cooling of inlet air in natural draft dry cooling towers. Appl. Therm. Eng. 2013, 61, 416-424. [CrossRef]

26. Beji, T.; Zadeh, S.E.; Maragkos, G.; Merci, B. Influence of the particle injection rate, droplet size distribution and volume flux angular distribution on the results and computational time of water spray CFD simulations. Fire Saf. J. 2017, 91, 586-595. [CrossRef]

27. Volkov, R.S.; Strizhak, P.A. Planar laser-induced fluorescence diagnostics of water droplets heating and evaporation at hightemperature. Appl. Therm. Eng. 2017, 127, 141-156. [CrossRef]

28. Sazhin, S.S. Advanced models of fuel droplet heating and evaporation. Prog. Energy Combust. Sci. 2006, 32, 162-214. [CrossRef]

29. Chu, F.; Xiao, G.; Yang, G. Mass transfer characteristics and energy penalty analysis of MEA regeneration process in packed column. Sustain. Energy Fuels 2021, 5, 438-448. [CrossRef]

30. Jen, T.C.; Li, L.J.; Cui, W.Z.; Chen, Q.H.; Zhang, X.M. Numerical investigations on cold gas dynamic spray process with nanoand microsize particles. Int. J. Heat Mass Transf. 2005, 48, 4384-4396. [CrossRef]

31. Hou, Y.; Tao, Y.; Huai, X.; Guo, Z. Numerical characterization of multi-nozzle spray cooling. Appl. Therm. Eng. 2012, 39, 163-170. [CrossRef]

32. Chen, W.X.; Chong, D.T.; Yan, J.J.; Dong, S.C.; Liu, J.P. Numerical Investigation of Two-Phase Flow in Natural Gas Ejector. Heat Transf. Eng. 2014, 35, 738-745. [CrossRef]

33. Bailey, A.G.; Balachandran, W.; Williams, T.J. The rosin-rammler size distribution for liquid droplet ensembles. J. Aerosol. Sci. 1983, 14, 39-46. [CrossRef]

34. Li, T.; Pougatch, K.; Salcudean, M.; Grecov, D. Numerical modeling of an evaporative spray in a riser. Powder Technol. 2010, 201, 213-229. [CrossRef]

35. Li, C.; Deng, T.; Wen, Z.; Tian, T.; Li, G.; Zhang, Y.; Li, Z. Evaporation experiment and numerical simulation study of desulfurization wastewater in high-temperature raw gas. Chem. Eng. Res. Des. 2019, 146, 117-129. [CrossRef]

36. Tate, R.W. Some Problems Associated with the Accurate Representation of Droplet Size Distributions. In Proceedings of the 2nd International Conference on Liquid Atomization and Spray Systems, Madison, WI, USA, 20-24 June 1982. 
37. Panão, M.R.O.; Moreira, A.L.N. A real-time assessment of measurement uncertainty in the experimental characterization of sprays. Meas. Sci. Technol. 2008, 19. [CrossRef]

38. Sureshkumar, R.; Kale, S.R.; Dhar, P.L. Heat and mass transfer processes between a water spray and ambient air-I. Experimental data. Appl. Therm. Eng. 2008, 28, 349-360. [CrossRef]

39. Alkhedhair, A.; Jahn, I.; Gurgenci, H.; Guan, Z.; He, S.; Lu, Y. Numerical simulation of water spray in natural draft dry cooling towers with a new nozzle representation approach. Appl. Therm. Eng. 2016, 98, 924-935. [CrossRef]

40. Tissot, J.; Boulet, P.; Labergue, A.; Castanet, G.; Trinquet, F.; Fournaison, L. Experimental study on air cooling by spray in the upstream flow of a heat exchanger. Int. J. Therm. Sci. 2012, 60, 23-31. [CrossRef]

41. Panão, M.O.; Moita, A.S.; Moreira, A.L. On the statistical characterization of sprays. Appl. Sci. (Switzerland) 2020, 10, 6122. [CrossRef]

42. Sun, Z.; Yang, L.; Chen, S.; Bai, L.; Wu, X. Promoting the removal of fine particles and zero discharge of desulfurization wastewater by spray-turbulent agglomeration. Fuel 2020, 270, 117461. [CrossRef] 